\title{
Panorama da agricultura orgânica e dos agrotóxicos no Brasil: uma análise a partir dos censos 2006 e 2017
}

\author{
Overview of organic agriculture and pesticides in Brazil: an analysis \\ from the 2006 and 2017 censuses \\ Taíse Fátima Mattei ${ }^{1}$ (D). Ednaldo Michellon² (1) \\ 1'Instituto Federal do Paraná, São Lourenço do Oeste (SC), Brasil. E-mail: taise_mattei_slo@hotmail.com \\ 2Programa de Pós-graduação em Economia, Universidade Estadual de Maringá (UEM), Maringá (PR), Brasil. E-mail: emichellon@ \\ uem.br
}

Como citar: Mattei, T. F., \& Michellon, E. (2021). Panorama da agricultura orgânica e dos agrotóxicos no Brasil: uma análise a partir dos censos 2006 e 2017. Revista de Economia e Sociologia Rural, 59(4), e222254. https://doi. org/10.1590/1806-9479.2021.222254

Resumo: Frente ao debate relativamente antigo sobre o uso de agrotóxicos e práticas agrícolas mais sustentáveis, este artigo se propõe a fazer um panorama da agricultura orgânica e do uso de agrotóxicos no Brasil, a partir dos Censos Agropecuários de 2006 e 2017. A pesquisa se caracterizou como comparativa descritiva e focou a análise nos estabelecimentos agropecuários. Os principais resultados indicaram que, em 2006, cerca de 27\% dos estabelecimentos agropecuários usavam agrotóxicos; já em 2017, esse percentual subiu para 33\%. As regiões líderes em estabelecimentos com uso de agrotóxicos em 2006 e 2017 eram Sul e Nordeste. Os estados Rio Grande do Sul e Paraná eram os estados onde se encontravam o maior número de estabelecimentos produzindo com agrotóxicos do total brasileiro, nos dois Censos analisados. Com relação à agricultura orgânica, percebeu-se que houve uma redução relativa do número de estabelecimentos com agricultura orgânica no Brasil nesse período, embora seja preciso fazer ressalvas quanto à possibilidade de superestimação das informações. Em 2006, estavam, na região Nordeste, 46,7\% desses estabelecimentos, $21 \%$ na região Sul e 20\% na região Sudeste. Já em 2017, 28\% estavam na região Sudeste, 27\% na região Nordeste e $20 \%$ na região Sul.

Palavras-chave: agroecologia, estabelecimentos agropecuários, regiões, sustentabilidade.

\begin{abstract}
Given the relatively old debate on the use of pesticides and more sustainable agricultural practices, this article aims to provide an overview of organic agriculture and the use of pesticides in Brazil from the 2006 and 2017 Agricultural Censuses. The research was characterized as a descriptive comparison and focused the analysis on agricultural establishments. The main results indicated that in 2006 about 27\% of agricultural establishments used pesticides, in 2017, this percentage rose to 33\%. The leading regions in establishments using pesticides in 2006 and 2017 were the South and Northeast. The states of Rio Grande do Sul and Paraná were the states where the largest number of establishments producing pesticides of the Brazilian total were found in the two Censuses analyzed. Concerning organic agriculture, there was a relative reduction in the number of establishments with organic agriculture in Brazil in this period, although it is necessary to make reservations regarding the possibility of overestimating the information. In 2006, 46.7\% of these establishments were in the Northeast, 21\% in the South, and 20\% in the Southeast. In 2017, 28\% were in the Southeast, $27 \%$ in the Northeast, and $20 \%$ in the South.
\end{abstract}

Keywords: agroecology, agricultural establishments, regions, sustainability.

\section{INTRODUÇÃO}

Uso de agrotóxicos e agricultura orgânica são temas bastante discutidos tanto no meio acadêmico como no meio social. Existe um debate relativamente antigo sobre o uso de agrotóxicos versus uma prática agrícola mais sustentável. Nessa esfera de diálogos sobre 
atividades mais saudáveis de agricultura, a agroecologia como ciência e a agricultura orgânica como prática têm peso bastante expressivo.

Os agrotóxicos - ou, também, como são chamados, venenos, defensivos agrícolas e agroquímicos - são substâncias químicas sintéticas usadas para controlar pragas e doenças em plantas e animais, permitindo, assim, maior produtividade dos cultivos. O uso dessas substâncias é bastante remoto, tendo registros de produtos com essa finalidade desde a Antiguidade. A partir da Segunda Guerra Mundial, a produção e o uso de agrotóxicos se expandiram em escala global dada a necessidade cada vez maior de aumentar a produção mundial de alimentos. $\mathrm{Na}$ década de 1950 e no início da década de 1960, surgiram, no entanto, os primeiros estudos para reavaliação dos problemas e da segurança dos produtos utilizados como agrotóxicos. Os riscos apontados fizeram emergir mudanças nas práticas e debates para uso de alternativas menos impactantes para a saúde e o meio ambiente. Os principais efeitos adversos do uso indiscriminado dessas substâncias são poluição do solo e dos recursos hídricos, mutações de espécies animais, desenvolvimento de doenças graves, intoxicações e contaminações, entre outros.

A agricultura orgânica, por outro lado, é uma atividade de produção que procura manter a saúde do solo, dos ecossistemas e das pessoas, a partir da não utilização de agrotóxicos e métodos agressivos para solo, plantas e animais. A história da agricultura orgânica está ligada ao pesquisador inglês Albert Howard, na década de 1920. No entanto, entre as décadas de 1930 e 1970, esta prática espalhou-se por vários países, até que os produtos orgânicos começaram a ser comercializados em escala mundial, a partir dos anos 1990.

O Brasil é o maior consumidor de agrotóxicos do mundo e, atualmente, também ocupa o primeiro lugar em importações desses produtos, sendo a China o país que mais os exporta. Já com relação à agricultura orgânica, em 2016, o Brasil possuía cerca de 19 mil unidades controladas, que afirmavam seguir as práticas da agricultura orgânica, envolvendo pequenas e grandes unidades de produção e processamento. Nesse mesmo período, havia no mundo cerca de 57,8 milhões de hectares com produção orgânica e os países que mais possuíam essas terras eram Austrália, Argentina e China (Pelaez et al., 2016; Federação Internacional dos Movimentos de Agricultura Orgânica, 2018b).

Diante desse contexto, este artigo procura responder ao seguinte questionamento: qual é o panorama da agricultura orgânica e do uso de agrotóxicos no Brasil, em 2017, frente a 2006? Dessa forma, o trabalho busca analisar dados sobre os estabelecimentos com agricultura orgânica e uso de agrotóxicos dos Censos Agropecuários de 2006 e 2017, e fazer um comparativo, buscando identificar a evolução desses dois segmentos. Além disso, alerta-se para a possibilidade de superestimação das informações sobre estabelecimentos orgânicos, segundo os Censos, dadas as evidências conflitantes.

Este trabalho caracteriza-se como comparativo descritivo e é um dos primeiros a utilizar dados do Censo Agropecuário 2017, para analisar esta temática. Além do mais, torna-se necessário atualizar os dados sobre a evolução do uso de agrotóxicos no Brasil, bem como fazer um panorama e um mapeamento dos estabelecimentos com agricultura orgânica. Ademais, as discussões sobre uso de agrotóxicos e expansão da agricultura orgânica sempre são importantes na literatura.

O artigo está organizado em cinco seções, além desta introdução. Na próxima seção, são abordados brevemente os agrotóxicos e as suas características. A seção 3 relata sobre a agricultura orgânica. A metodologia é apresentada na seção 4. Posteriormente, nas seções 5 e 6 , apresentam-se os resultados e as considerações finais da pesquisa. 


\section{AGROTÓXICOS}

O uso de substâncias químicas para controlar pragas e doenças em plantas e animais remonta à Antiguidade Clássica. Mas, no final do século XIX e no início do século XX, ocorreu expansão no uso desses produtos, com a chamada primeira geração dos agrotóxicos, sendo utilizados produtos à base de flúor, arsênio, mercúrio, selênio, chumbo e outros. Contudo, a partir da Segunda Guerra Mundial, a evolução da indústria química permitiu proliferação em larga escala dos agrotóxicos sintéticos, principalmente nos EUA e na Europa. Vários produtos foram desenvolvidos durante a Guerra por empresas americanas e alemãs, os quais, depois, deram origem a vários tipos de inseticidas e pesticidas (Alves Filho, 2002).

As primeiras fábricas de agrotóxicos no Brasil datam da metade da década de 1940. Durante os anos de 1954 a 1960, foi significativo o número de registros de novos produtos no Ministério da Agricultura. No entanto, o primeiro parque industrial de agrotóxicos surgiu na década de 1970, com a criação do Programa Nacional de Defensivos Agrícolas (Alves Filho, 2002; Terra, 2008). Porém, apenas em 1989, foi aprovada pelo Congresso Nacional a Lei 7.802, conhecida como Lei dos Agrotóxicos, que versava sobre produção, armazenamento, utilização, comercialização e outras providências, sendo um pouco mais rigorosa para a liberação de registros de produtos.

No Brasil, são considerados agrotóxicos todos os produtos e os agentes de processos físicos, químicos ou biológicos que são destinados para produção, armazenamento e beneficiamento de produtos agrícolas, nas pastagens, nas florestas, nos ambientes urbanos, hídricos e naturais, cuja finalidade seja preservar a flora ou a fauna da ação danosa dos seres vivos considerados nocivos (Brasil, 1989). Os agrotóxicos são produzidos principalmente a partir de derivados do petróleo e de minerais, como cloro, enxofre, nitrogênio, bromo fósforo, entre outros.

Embora atualmente sejam conhecidos os vários problemas do uso de agrotóxicos para os seres vivos e a saúde humana, ainda existem argumentos favoráveis para sua utilização. Dentre esses, podem-se citar: os agrotóxicos controlam doenças que podem ser transmitidas a seres humanos; os agrotóxicos aumentam a disponibilidade de alimentos e reduzem seus custos; aumentam a produtividade e os lucros dos produtores; são mais rápidos e eficientes no controle de pragas e doenças, entre outros (Alves Filho, 2002). No entanto, alguns autores, como Londres (2011), relatam sobre a ineficiência desse sistema produtivo, dado que as pragas, com o tempo, se tornam resistentes e permanecem nas áreas, e porque, ao longo do tempo, a agricultura tem obtido resultados cada vez piores no quesito produtividade/custos.

O comércio e o uso mundial de agrotóxicos aumentaram a uma taxa anual de 10\% entre as décadas de 1950 e 1980. Mais da metade dos agrotóxicos produzidos nesse período foram consumidos pelos EUA e pela Europa Ocidental (Alves Filho, 2002). Terra (2008) relata que a indústria de agrotóxicos implantada no Brasil cresceu de forma significativa entre 1975 e 2007, acumulando elevações nas vendas de 13,1\% ao ano, entre 1988 e 1999, e de aproximadamente 21\% entre 2001 e 2005. Durante todo o período de 1975 a 2007, o Brasil sempre esteve entre os seis maiores mercados de agrotóxicos do mundo.

Segundo Azevedo (2018), em 2009, o Brasil constituiu o maior mercado consumidor de agrotóxicos do mundo e, de 2003 a 2008, houve um uso abusivo dessas substâncias, com um aumento de 127\%. Pelaez et al. (2016) apontam que, de 2000 a 2013, o comércio mundial de agrotóxicos cresceu cerca de $220 \%$, devido basicamente ao aumento da produção de commodities agrícolas que usam intensivamente esses insumos, como milho, soja, algodão e cana-de-açúcar. Nesse período, a China tornou-se o maior exportador mundial de agrotóxicos. Já o Brasil apresentou a maior taxa de crescimento das importações de agrotóxicos no período, tornando-se, a partir de 2012, o maior importador mundial e, desde 2009, o maior mercado consumidor. 
Uma das principais características do mercado de agrotóxicos é a elevada concentração. 0 mercado mundial é controlado por poucas empresas transnacionais e, devido a isso, tornase bastante internacionalizado. Segundo Pelaez et al. (2016), em 2014, cerca de 13 empresas multinacionais foram responsáveis por $90 \%$ das vendas mundiais. Esse mercado exige elevados investimentos em pesquisa e desenvolvimento, e também se caracteriza por um segmento altamente tecnológico.

\section{AGRICULTURA ORGÂNICA}

Para a Federação Internacional dos Movimentos de Agricultura Orgânica (IFOAM) (Federação Internacional dos Movimentos de Agricultura Orgânica, 2018a), a agricultura orgânica não é apenas uma forma de gerir naturalmente o solo, as plantas e os animais, mas também um paradigma histórico criado para sustentar a vida na Terra e baseado nos desafios da agricultura industrializada. Whitacker (2012) afirma que a agricultura orgânica é uma alternativa àquela agricultura que surgiu após a Segunda Guerra Mundial e que teve impulso com a Revolução Verde, período em que as tecnologias usadas na Guerra foram convertidas para elevar a produtividade da agricultura. Nesse período, cresceu exponencialmente o uso das inovações para desenvolvimento de inseticidas, pesticidas, herbicidas, adubos químicos e tantos outros, tornando a agricultura dependente da indústria química.

Caporal (2009) relata que um dos grandes apelos da agricultura moderna foi a diminuição da fome e que, devido ao fim da Guerra, dever-se-iam mudar as preocupações mundiais para o abastecimento de alimentos, fornecendo maior quantidade e qualidade dos produtos. No entanto, com o desenvolvimento desse sistema, observou-se, em escala global, que a fome não foi combatida e que a agricultura convencional não foi capaz de superar os desafios alimentares, e, pelo contrário, intensificou os problemas da destruição da natureza. Foi nesse contexto que, a partir dos anos 1960, se intensificaram os movimentos a favor de uma agricultura alternativa, tendo ganhado destaque a que hoje é chamada de agricultura orgânica.

O termo agricultura orgânica nem sempre foi usado dessa forma. Segundo Fonseca (2009), nas décadas de 1970 e 1980, a agricultura orgânica era chamada de agricultura alternativa, por falta de denominação mais apropriada para o processo. Essa terminologia se referia às formas de agricultura não industriais. Houve intenso debate internacional sobre a melhor terminação para designar esse tipo de agricultura. Algumas das sugestões eram agricultura ecológica, biológica, entre outras, mas a terminologia orgânica acabou sendo adotada pelas normas internacionais e a agroecologia evoluiu como ciência.

Segundo a IFOAM (Federação Internacional dos Movimentos de Agricultura Orgânica, 2018a), a agricultura orgânica é definida como um sistema que procura manter a saúde do solo, dos ecossistemas e das pessoas. Esse sistema propõe alternativas ao uso de insumos com efeitos adversos e depende de processos ecológicos e da biodiversidade. O objetivo dela é beneficiar o meio ambiente com ciência e inovação, e promover relacionamento mais equilibrado e justo entre ser humano e natureza, permitindo melhor qualidade de vida a todos os envolvidos.

Azevedo (2018) aponta que a agricultura orgânica, principalmente aquela familiar, tem intuito de promover a vida com qualidade, além de preservar os valores sociais. Esta tornase também uma estratégia de reinserção da natureza no meio rural e na atividade agrícola, porque o sistema orgânico respeita os princípios naturais dos ecossistemas.

A história da agricultura orgânica está atrelada ao pesquisador inglês Albert Howard, na década de 1920. Este, em viagem à Índia, conheceu as práticas de compostagem e adubação orgânica pelos camponeses e as relatou posteriormente em seu livro Um testamento agrícola, de 1940. Na mesma época, Claude Aubert, na França, propagou as práticas da agricultura 
biológica por meio do uso de rotação de culturas, adubos verdes, controle natural de pragas e doenças, além do não uso de fertilizantes e adubos sintéticos. Além desses, Rudolf Steiner, na Alemanha, divulgou as bases da agricultura biodinâmica, buscando equilíbrio na produção e uso apenas de elementos orgânicos nas propriedades agrícolas (Ormond et al., 2002; Assis, 2005).

Entre as décadas de 1930 até 1970, estas práticas se disseminaram por vários outros países. Em 1935, no Japão, Mokiti Okada definiu filosoficamente o que seria uma agricultura natural, sendo aquela que valorizava o solo como fonte primordial de vida. Bill Mollison, em 1971, na Austrália, conceituou permacultura, que também seria um modelo de agricultura integrada com o ambiente. A partir da década de 1970, surgiu a agroecologia e os produtos orgânicos começaram a ser comercializados na Europa. O movimento se consolidou no final da década de 1980, tendo seu maior crescimento em meados dos anos 1990, com a normalização e padronização de produção, processamento e comercialização (Ormond et al., 2002; Assis, 2005).

Dentro dessa discussão, o Quadro 1 apresenta uma síntese das escolas da agricultura sustentável, segundo Sversutti et al. (2009) e Moraes \& Michellon (2012).

Quadro 1- Escolas da Agricultura Sustentável

\begin{tabular}{|l|l|}
\multicolumn{2}{c|}{ Escolas } \\
\hline Agricultura Biodinâmica & Surgiu na Alemanha, com Rudolf Steiner, em 1924. \\
\hline Agricultura Orgânica & Surgiu com Albert Howard, entre 1920-40. \\
\hline Agricultura Natural & Surgiu no Japão, pela Igreja Messiânica, entre 1930-40. \\
\hline Agricultura Agrobiológica & Surgiu na França, com Claude Aubert, na década de 1960. \\
\hline Permacultura & Surgiu na Austrália, com Bill Mollison, nos anos 1970. \\
\hline Agroecologia & $\begin{array}{l}\text { Surgiu nos EUA e na América Latina, com Miguel Altieri, José } \\
\text { Lutzemberger, Ana Maria Primavesi, Stephen Gliessman, dentre outros, } \\
\text { a partir dos anos 1970. }\end{array}$ \\
\hline
\end{tabular}

Fonte: Elaborada pelos autores com base em Sversutti et al. (2009) e Moraes \& Michellon (2012).

Fonseca (2009) aponta que a institucionalização da agricultura orgânica no mundo se deu por volta de 1972, com a criação da IFOAM, e com a publicação das primeiras normas, em 1978. As normas criadas serviram de base para a comercialização dos produtos orgânicos no mundo até a década de 1990 e para o surgimento de outras normas e regulamentos em diferentes países.

A França foi o primeiro país a regulamentar a agricultura orgânica, nos anos 1980. No início da década de 1990, no mesmo sentido, foram criados os regulamentos técnicos para a produção orgânica de origem vegetal da Comunidade Econômica Europeia, que era, na época, o maior mercado de orgânicos do mundo (Ormond et al., 2002; Fonseca, 2009).

De acordo com Ormond et al. (2002, p. 9):

Com o crescimento da consciência de preservação ecológica e a busca por alimentação cada vez mais saudável, houve expansão da clientela dos produtos orgânicos e, na década de 80, organizaram-se muitas das cooperativas de produção e consumo de produtos naturais hoje em atividade, bem como os restaurantes dedicados a esse tipo de alimentação.

A partir dos anos 1990, a venda de produtos naturais ${ }^{1}$ se expandiu em feiras e, no fim dessa década, os orgânicos passaram a ser vendidos com força nos supermercados. Mas, nos anos 2000, os produtos orgânicos ainda representavam parcela pequena do comércio total de alimentos. Entretanto, nos dias atuais, os produtos orgânicos possuem mercado promissor e em expansão.

1 Produto natural, neste trabalho, é tratado como sinônimo de produto orgânico. 
A maior regulamentação para esse setor surgiu fruto do aumento da demanda pelos consumidores e do interesse dos produtores em expandir seus mercados. Para Campanhola \& Valarini (2001), vários são os fatores que impulsionaram a demanda por produtos orgânicos no Brasil e no mundo. Dentre eles, podem-se citar: a preocupação dos consumidores com alimentação saudável, a mobilização de movimentos ambientalistas organizados para a preservação do meio ambiente, a influência de grupos organizados contrários ao domínio da agricultura moderna, entre outros. Além disso, a agricultura orgânica tem se mostrado um negócio bastante vantajoso, principalmente para a inserção de pequenos agricultores no mercado. Como a produção de commodities requer escala de produção para ser viável, o pequeno produtor pode recorrer à produção orgânica como uma alternativa. Embora seja menos produtiva que a agricultura convencional, a produção orgânica permite maior emprego de mão de obra e melhor custo-benefício, já que os preços dos produtos orgânicos se encontram, na maioria das vezes, acima dos preços dos convencionais. Ademais, como a produção orgânica é um nicho de mercado, ela visa atender a uma demanda específica, que está mais disposta a pagar um preço mais elevado pelo produto.

Apesar das grandes vantagens desse sistema orgânico, também existe alguns desafios que os produtores orgânicos devem enfrentar. A dificuldade de estabelecimento de contratos duradouros de fornecimento é um deles, devido à maior irregularidade da produção. Somados a isso, há também: relativa escassez de pesquisas científicas; falta de assistência técnica da rede pública, embora Assistência Técnica e Extensão Rural (ATER) tenha contribuído para uma melhora nesse quesito; maior necessidade de mão de obra familiar ou de terceiros, o que pode elevar o custo de produção; dificuldades de acesso ao crédito bancário; custos de certificação, entre outros (Campanhola \& Valarini, 2001).

No ano de 2006, os países com o maior número de unidades de produção orgânica certificadas eram México (12 mil unidades), Indonésia (45 mil unidades), Itália (36 mil unidades), Filipinas (35 mil unidades) e Uganda (34 mil unidades). As maiores áreas com culturas encontravam-se na Europa, seguida dos Estados Unidos. O Brasil tinha cerca de 19 mil unidades controladas que afirmavam seguir as práticas da agricultura orgânica, envolvendo pequenas e grandes unidades de produção e processamento. Em 2016, segundo a IFOAM (Federação Internacional dos Movimentos de Agricultura Orgânica, 2018b), 178 países do mundo tinham atividade de agricultura orgânica, sendo 87 com regulamentações. Havia, no mundo, cerca de 57,8 milhões de hectares com agricultura orgânica e os países que mais possuíam essas terras eram Austrália, Argentina e China. Além disso, em 2016, os países com maior número de unidades produtoras eram Índia (835 mil unidades), Uganda (210.352 unidades) e México (210 mil unidades).

Portanto, a história da agricultura - que hoje é denominada de orgânica - remonta do início do século XX e sua difusão se deu em oposição ao sistema da agricultura convencional, a partir da década de 1960. A regulamentação e a normalização permitiram que os produtos orgânicos fossem comercializados em escala global e cada vez mais se percebe a evolução dessa prática de agricultura, em todo o mundo.

\section{METODOLOGIA}

Para acompanhar a evolução do uso de agrotóxicos e da produção orgânica no Brasil, são utilizados dados dos Censos Agropecuários de 2006 e 2017, disponibilizados pelo Instituto Brasileiro de Geografia e Estatística (Instituto Brasileiro de Geografia e Estatística, 2006, 2017). A comparação dos dados é de ordem regional e estadual, e a pesquisa se caracteriza como descritiva comparativa.

As informações sobre agricultura orgânica estiveram presentes pela primeira vez no Censo Agropecuário de 2006. No referido Censo, foi coletada a informação referente à pergunta: No 
estabelecimento, se faz agricultura orgânica? (conforme definido na Lei n 10.831 de 23 de dezembro de 2003 (Brasil, 2003). Na resposta, era possível identificar se o estabelecimento fazia agricultura orgânica e se era ou não certificado por entidade certificadora. No Censo mais recente, de 2017, também foram coletadas informações sobre se o estabelecimento fazia agricultura orgânica (segundo a definição da Lei $n^{\circ} 10.831^{2}$ ), sendo possível identificar a origem da produção orgânica, se animal ou vegetal. No entanto, não foi disponibilizada a resposta segundo a certificação, dado que, segundo gerentes técnicos do Censo, todos os que responderam positivamente quanto à prática de agricultura orgânica, em 2017, necessariamente eram certificados.

As informações coletadas dos Censos foram selecionadas de modo a permitir a comparação entre os dois períodos. Vale a pena mencionar que, no momento da pesquisa, só haviam sido disponibilizados dados preliminares do Censo Agropecuário de 2017 pelo IBGE, sendo estes passíveis de alterações posteriores. Além disso, estavam disponíveis dados apenas do número de estabelecimentos com agricultura orgânica, não sendo possível ainda obter informação sobre a área desses estabelecimentos.

As variáveis para análise são: número de estabelecimentos agropecuários com e sem agricultura orgânica, e certificados ou não (para 2006); número de estabelecimentos agropecuários segundo o uso de agrotóxicos; e, exclusivamente para o ano de 2006, área dos estabelecimentos com uso de agrotóxicos e de agricultura orgânica. Depois de coletadas as informações, elas foram tabeladas, organizadas e foram feitas as análises descritivas comparativas.

\section{DESCRIÇÃO E ANÁLISE DOS RESULTADOS}

Esta seção se dedica a mostrar os dados coletados dos Censos de 2006 e 2017, e fazer uma análise comparativa evolutiva sobre a agricultura orgânica e os agrotóxicos, no Brasil. A Tabela 1 apresenta o número de estabelecimentos agropecuários nas regiões brasileiras que praticavam agricultura orgânica frente aos que não a praticavam nos anos de 2006 e 2017.

Tabela 1 - Número e percentual de estabelecimentos agropecuários com e sem agricultura orgânica em 2006 e 2017, nas grandes regiões brasileiras

\begin{tabular}{lcccccccccc}
\multirow{2}{*}{ Região } & \multicolumn{1}{c}{$\mathbf{2 0 0 6}$} & \multicolumn{7}{c}{$\mathbf{2 0 1 7}$} \\
\cline { 2 - 10 } & Com & $\%$ & Sem & $\%$ & Total & Com & $\%$ & Sem & $\%$ & Total \\
Norte & 6.133 & 1,29 & 469.645 & 98,71 & 475.778 & 7.934 & 1,37 & 572.512 & 98,63 & 580.446 \\
Nordeste & 42.236 & 1,72 & 2.411 .824 & 98,28 & 2.454 .060 & 19.148 & 0,82 & 2.303 .347 & 99,18 & 2.322 .495 \\
Sudeste & 18.715 & 2,03 & 903.382 & 97,97 & 922.097 & 19.684 & 2,03 & 949.574 & 97,97 & 969.258 \\
Sul & 19.276 & 1,92 & 986.927 & 98,08 & 1.006 .203 & 14.116 & 1,65 & 839.116 & 98,35 & 853.232 \\
Centro- & 4.138 & 1,30 & 313.360 & 98,70 & 317.498 & 7.834 & 2,26 & 338.887 & 97,74 & 346.721 \\
Oeste & & & & & & & & & & \\
BRASIL & 90.498 & 1,75 & 5.085 .138 & 98,25 & 5.175 .636 & 68.716 & 1,35 & 5.003 .436 & 98,65 & 5.072 .152 \\
\hline
\end{tabular}

Fonte: Elaborada pelos autores a partir dos dados dos Censos Agropecuários de 2006 e 2017 (Instituto Brasileiro de Geografia e Estatística, 2006, 2017).

Primeiramente, nota-se que o número de estabelecimentos agropecuários reduziu $2 \%$ de 2006 para 2017, o que pode ser explicado pelo aumento da área das propriedades rurais e

\footnotetext{
2 Em 2003, foi publicada a Lei n 10.831, que dispunha sobre a agricultura orgânica no Brasil. Esta lei definia a agricultura orgânica como um sistema que tinha por objetivo a sustentabilidade econômica e ecológica, a maximização dos benefícios sociais e a minimização da dependência de energias não renováveis. Apoiava também o uso de métodos culturais, biológicos e mecânicos em oposição ao uso de materiais sintéticos e organismos geneticamente modificados, e firmava o compromisso de proteção ao meio ambiente (Brasil, 2003).
} 
pela diminuição das pequenas propriedades. O número de estabelecimentos que praticava agricultura orgânica no Brasil, em 2006, era pequeno, apenas 1,75\% do total de estabelecimentos, e ocorreu queda no percentual relativo desses estabelecimentos em 2017, se comparado com 2006. Do total de estabelecimentos de cada região, em 2006, as que apresentavam maior percentual com agricultura orgânica, embora baixos, eram Sudeste e Sul. No entanto, em 2017, ainda com baixas participações, Centro-Oeste e Sudeste foram os destaques, com redução importante dos estabelecimentos com orgânicos na região Nordeste, se comparado com 2006.

Para Madail et al. (2011), o que vem acontecendo no Brasil é a existência de produtos orgânicos certificados, seguindo todos os procedimentos necessários, e muitos outros produtos orgânicos submetidos a alguma forma de registro e controle social, mas sem certificação, que são aceitos pelos consumidores. A falta de compatibilização dos mecanismos de controle e garantia da qualidade orgânica é um problema relevante para o desenvolvimento desse segmento no Brasil.

Segundo Azevedo (2018), devido à baixa demanda, se comparados com os produtos convencionais, os produtos orgânicos ainda não são competitivos no mercado. Os alimentos orgânicos recebem um preço mais elevado e isto deve ser entendido do ponto de vista dos benefícios ambientais e sociais que geram, e também para que o produtor se fortaleça e se consolide na atividade.

A Figura 1 mostra a participação relativa das regiões no total de estabelecimentos com agricultura orgânica do Brasil, em 2006 e 2017. Embora a região Centro-Oeste apresentasse poucos estabelecimentos com essa atividade, estes eram de grandes extensões.

Em 2006, estavam, na região Nordeste, 46,7\% desses estabelecimentos, $21 \%$ na região Sul e $20 \%$ na região Sudeste. Já em 2017, 28\% estavam na região Sudeste, 27\% na região Nordeste e $20 \%$ na região Sul. Percebe-se que ocorreu uma modificação locacional dessa atividade. Nos dois anos analisados, a região Centro-Oeste era a que menos possuía estabelecimentos com agricultura orgânica, tal fato podendo ser explicado pela existência de grandes propriedades rurais e também pela grande produção de commodities agrícolas. A região Nordeste se destaca, pois a agricultura extravista é incluída como orgânica (Madail et al., 2011).

$2006 \quad 2017$

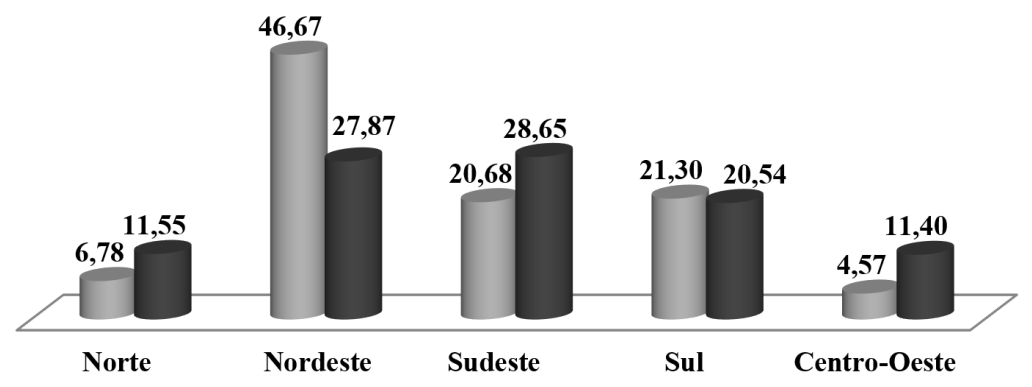

Figura 1 - Participação relativa das regiões no total de estabelecimentos com agricultura orgânica do Brasil. Fonte: Elaborada pelos autores a partir dos dados dos Censos Agropecuários de 2006 e 2017 (Instituto Brasileiro de Geografia e Estatística, 2006, 2017).

Além disso, em 2006, apenas 1,48\% (4.935.470 hectares) da área total da agricultura do Brasil era usada para a agricultura orgânica. A maior quantidade de área com agricultura orgânica estava na região Nordeste (1.574.006 hectares), seguida pela região Centro-Oeste (1.233.149 hectares). A Figura 2 mostra a distribuição dessas terras entre as regiões brasileiras.

Como já ressaltado, no momento da pesquisa, ainda não estavam disponíveis informações sobre a área dos estabelecimentos com agricultura orgânica para o Censo Agropecuário de 
2017. Porém, Madail et al. (2011), afirmam que a área agrícola brasileira considerada com produção orgânica vem aumentando devido à incorporação de áreas de pastagens e de produtos florestais não madeireiros.

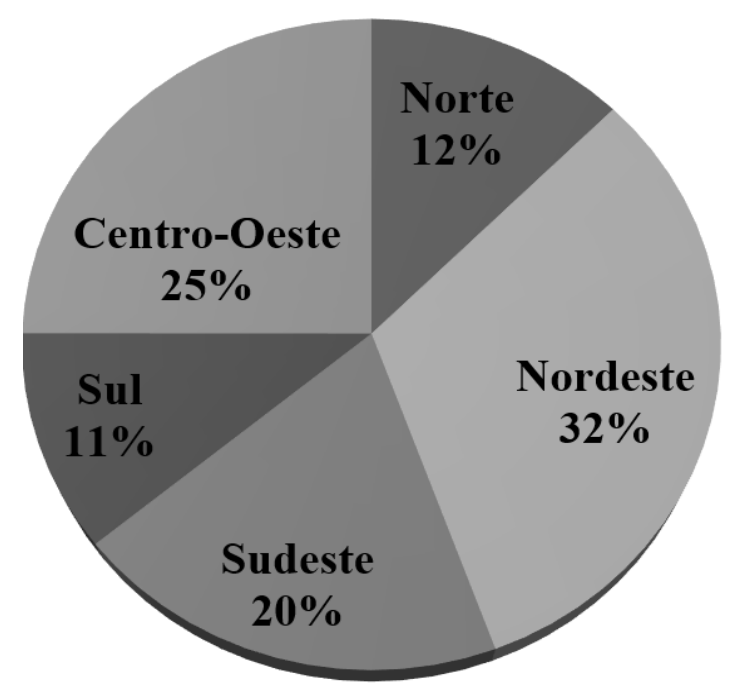

Figura 2 - Distribuição da área agrícola brasileira com produção orgânica entre as regiões, em 2006. Fonte: Elaborada pelos autores a partir dos dados dos Censos Agropecuários de 2006 e 2017 (Instituto Brasileiro de Geografia e Estatística, 2006, 2017).

A Tabela 2 apresenta o número de estabelecimentos agropecuários com agricultura orgânica que possuíam certificação em 2006 nas regiões brasileiras. Essas informações não foram disponibilizadas pelo Censo 2017.

Tabela 2 - Número de estabelecimentos agropecuários com agricultura orgânica certificados e não certificados em 2006, nas grandes regiões brasileiras

\begin{tabular}{lccccc} 
& \multicolumn{5}{c}{$\mathbf{2 0 0 6}$} \\
\cline { 2 - 5 } \multicolumn{1}{c}{ Regiões } & Certificados & $\%$ & $\begin{array}{c}\text { Não } \\
\text { Certificados }\end{array}$ & $\%$ & Total \\
\cline { 2 - 6 } Norte & 351 & 5,72 & 5.782 & 94,28 & 6.133 \\
Nordeste & 1.218 & 2,88 & 41.018 & 97,12 & 42.236 \\
Sudeste & 1.366 & 7,30 & 17.349 & 92,70 & 18.715 \\
Sul & 1.924 & 9,98 & 17.352 & 90,02 & 19.276 \\
Centro-Oeste & 247 & 5,97 & 3.891 & 94,03 & 4.138 \\
BRASIL & 5.106 & 5,64 & 85.392 & 94,36 & 90.498 \\
\hline
\end{tabular}

Fonte: Elaborada pelos autores a partir dos dados dos Censos Agropecuários de 2006 e 2017 (Instituto Brasileiro de Geografia e Estatística, 2006, 2017).

Do total de estabelecimentos com agricultura orgânica no Brasil, em 2006, apenas 5,64\% eram certificados. Em relação ao total de estabelecimentos de cada região, as regiões Sul e Sudeste se destacavam com maior número de certificações. Analisando-se relativamente os estabelecimentos agropecuários certificados das regiões com o total brasileiro certificado, $37,6 \%$ e $26,7 \%$ destes estavam nas regiões Sul e Sudeste, respectivamente. Segundo Lourenço et al. (2017), o baixo número de estabelecimentos certificados pode estar 
relacionado à falta de acompanhamento técnico dos agricultores e das práticas orgânicas de produção.

Madail et al. (2011) apontam que a produção orgânica brasileira certificada enfrenta limitações devido aos problemas de organização, de oferta da produção e de falta de estímulo das políticas públicas. Para Azevedo (2018), a comercialização dos produtos orgânicos é o maior entrave para os produtores no Brasil. Muitas vezes, a venda direta dos orgânicos se torna inviável pela distância das propriedades até os pontos de venda, pela falta de regularidade da qualidade dos produtos e pelo preço final nem sempre atrativo.

Azevedo (2018) aponta ainda que os grandes supermercados impõem muitas barreiras para a comercialização dos produtos orgânicos. Estas vão desde exigências de padronização, uso de embalagens próprias, contratos regulares de entrega, até margens elevadas nos produtos, o que acaba por elitizar o consumo de orgânicos. As alternativas aos produtores são diversificar os circuitos de comercialização e, nesse sentido, as feiras e vendas diretas, bem como as associações, podem fortalecer esse processo. Políticas públicas que forneçam apoio e condições necessárias são extremamente importantes, conjugadas com ações da iniciativa privada.

Fazendo um contraponto com as informações dos Censos, em 2017, o Ministério da Agricultura, Pecuária e do Abastecimento (MAPA) publicou um documento indicando o número de unidades controladas de produção orgânica no Brasil e em seus estados. Segundo esse documento, havia, no Brasil, 11.194 unidades controladas, incluindo certificações no exterior (Brasil, 2017). No mesmo sentido, em 2018, o Serviço Brasileiro de Apoio às Micro e Pequenas Empresas (SEBRAE) informou, em uma publicação, que o Brasil possuía cerca de 16 mil produtores orgânicos (Serviço Brasileiro de Apoio às Micro e Pequenas Empresas, 2018). Comparando-se com as informações divulgadas pelo Censo, embora sejam de 2006, há relativa discrepância das informações.

Uma análise importante a se fazer é que, embora na pergunta dos Censos, tanto de 2006 como de 2017, admitiu-se a definição de agricultura orgânica segundo a Lei n 10.831 e recomendou-se ao recenseador não considerar como agricultura orgânica o sistema de produção em que o produtor, apesar de não usar adubos químicos e agrotóxicos, não tinha interesse ou desconhecia as técnicas específicas exigidas pelas instituições certificadoras de produtos orgânicos, e que a agricultura é considerada orgânica apenas mediante avaliação de instituição certificadora, salvo os casos de certificação facultativa, na prática, a avaliação do próprio produtor como produtor orgânico pode ir de encontro com as definições e práticas legais. Dessa forma, percebe-se o risco de que os dados sobre produção orgânica dos Censos sejam superestimados. A informação sobre a certificação ou não das propriedades orgânicas do Brasil no Censo de 2006 deixa claro essa incongruência entre teoria e prática. Se for levado em consideração que apenas estabelecimentos certificados são, de fato, produtores orgânicos, as estimativas de produção orgânica no Brasil estariam bastante viesadas. No entanto, não se pode ignorar o fato de que a certificação no Brasil ainda carece de melhorias, inclusive na questão dos custos e da alta burocracia. Em muitos casos, os produtores podem ser, de fato, produtores orgânicos, mas não são certificados por motivos de falta de atualização, alta burocracia, custos elevados, falta de informação, entre outros.

Continuando com a análise, a Tabela 3, por sua vez, apresenta o número de estabelecimentos agropecuários com e sem agricultura orgânica nos estados brasileiros, em 2006 e 2017, e o respectivo percentual do total de cada estado.

Tabela 3 - Número de estabelecimentos agropecuários com e sem agricultura orgânica em 2006 e 
2017, nos estados brasileiros

\begin{tabular}{|c|c|c|c|c|c|c|c|c|c|c|}
\hline \multirow{2}{*}{ Estados } & \multicolumn{5}{|c|}{2006} & \multicolumn{5}{|c|}{2017} \\
\hline & Com & $\%$ & Sem & $\%$ & Total & Com & $\%$ & Sem & $\%$ & Total \\
\hline Rondônia & 927 & 1,06 & 86.151 & 98,94 & 87.078 & 1.596 & 1,75 & 89.841 & 98,25 & 91.437 \\
\hline Acre & 485 & 1,65 & 28.998 & 98,35 & 29.483 & 1.276 & 3,42 & 36.067 & 96,58 & 37.343 \\
\hline Amazonas & 1.211 & 1,81 & 65.573 & 98,19 & 66.784 & 340 & 0,42 & 80.574 & 99,58 & 80.914 \\
\hline Roraima & 64 & 0,62 & 10.246 & 99,38 & 10.310 & 633 & 3,76 & 16.217 & 96,24 & 16.850 \\
\hline Pará & 2.362 & 1,06 & 219.667 & 98,94 & 222.029 & 3.988 & 1,42 & 277.716 & 98,58 & 281.704 \\
\hline Amapá & 29 & 0,82 & 3498 & 99,18 & 3.527 & 101 & 1,19 & 8.406 & 98,81 & 8.507 \\
\hline Tocantins & 1.055 & 1,87 & 55.512 & 98,13 & 56.567 & 0 & 0,00 & 63.691 & 100,00 & 63.691 \\
\hline Maranhão & 3.256 & 1,13 & 283.783 & 98,87 & 287.039 & 1.440 & 0,66 & 218.325 & 99,34 & 219.765 \\
\hline Piauí & 3.712 & 1,51 & 241.666 & 98,49 & 245.378 & 190 & 0,08 & 245.433 & 99,92 & 245.623 \\
\hline Ceará & 4.865 & 1,28 & 376.152 & 98,72 & 381.017 & 437 & 0,11 & 393.880 & 99,89 & 394.317 \\
\hline $\begin{array}{l}\text { Rio Gra } \\
\text { Norte }\end{array}$ & 2 & 2,73 & 80787 & 97 & & 1.870 & 2,95 & & 97,05 & 63.411 \\
\hline Paraíba & 3.362 & 2,01 & 163.924 & 97,99 & 167.286 & 1.883 & 1,15 & 161 & 98,85 & 163.217 \\
\hline Pernambuco & 6.425 & 2,11 & 298.365 & 97,89 & 304.790 & 7.234 & 2,57 & 274.441 & 97,43 & 281.675 \\
\hline Alagoas & 2.117 & 1,72 & 121.215 & 98,28 & 123.332 & 3.387 & 3,44 & 95.147 & 96,56 & 98.534 \\
\hline Sergipe & 1.039 & 1,03 & 99.568 & 98,97 & 100.607 & 1.195 & 1,28 & 92.138 & 98,72 & 93.333 \\
\hline Bahia & 15.194 & 2,00 & 746.364 & 98,00 & 761.558 & 1.512 & 0,20 & 761.108 & 99,80 & 762.620 \\
\hline Minas Gerais & 12.910 & 2,34 & 538.711 & 97,66 & 551.621 & 10.905 & 1,80 & 596.543 & 98,20 & 607.448 \\
\hline Espírito Santo & 1.466 & 1,74 & 82.895 & 98,26 & 84.361 & 1.522 & 1,41 & 106.488 & 98,59 & 108.010 \\
\hline Rio de Janeiro & 968 & 1,65 & 57.525 & 98,35 & 58.493 & 2.364 & 3,63 & 62.793 & 96,37 & 65.157 \\
\hline São Paulo & 3.371 & 1,48 & 224.251 & 98,52 & 227.622 & 4.893 & 2,59 & 183.750 & 97,41 & 188.643 \\
\hline Paraná & 7.528 & 2,03 & 363.535 & 97,97 & 371.063 & 7.056 & 2,31 & 298.059 & 97,69 & 305.115 \\
\hline Santa Catarina & 3.216 & 1,66 & 190.452 & 98,34 & 193.668 & 2.920 & 1,60 & 180.145 & 98,40 & 183.065 \\
\hline $\begin{array}{l}\text { Rio Grande do } \\
\text { Sul }\end{array}$ & 8.532 & 1,93 & 432.940 & 98,07 & 441.472 & 4.140 & 1,13 & 360.912 & 98,87 & 365.052 \\
\hline $\begin{array}{l}\text { Mato Grosso } \\
\text { do Sul }\end{array}$ & 753 & 1,16 & 64.111 & 98,84 & 64.864 & 1.317 & 1,86 & 69.393 & 98,14 & 70.710 \\
\hline Mato Grosso & 1.619 & 1,43 & 111.368 & 98,57 & 112.987 & 2.302 & 1,94 & 116.374 & 98,06 & 118.676 \\
\hline Goiás & 1.605 & 1,18 & 134.087 & 98,82 & 135.692 & 3.719 & 2,45 & 148.370 & 97,55 & 152.089 \\
\hline Distrito Federal & 161 & 4,07 & 3.794 & 95,93 & 3.955 & 496 & 9,45 & 4.750 & 90,55 & 5.246 \\
\hline
\end{tabular}

Fonte: Elaborada pelos autores a partir dos dados dos Censos Agropecuários de 2006 e 2017 (Instituto Brasileiro de Geografia e Estatística, 2006, 2017).

Em 16 estados, ocorreu aumento relativo do número de estabelecimentos com agricultura orgânica, porém os estados Amazonas, Tocantins, Maranhão, Piauí, Ceará, Paraíba, Bahia, Minas Gerais, Espírito Santo, Santa Catarina e Rio Grande do Sul tiveram esse percentual reduzido. Cinco desses estados que apresentaram redução do número de estabelecimentos com agricultura orgânica eram da região Nordeste, o que contribuiu para que essa região tivesse uma redução significativa nos estabelecimentos com orgânicos, nesse período. Nesta lista, chamam a atenção Ceará, Tocantins e Piauí, que praticamente não tinham mais estabelecimentos que produziam produtos orgânicos, em 2017.

A Figura 3 reúne informações para analisar a evolução do número de estabelecimentos com produção orgânica dos estados frente ao total nacional dos estabelecimentos orgânicos de 2006 e 2017. 


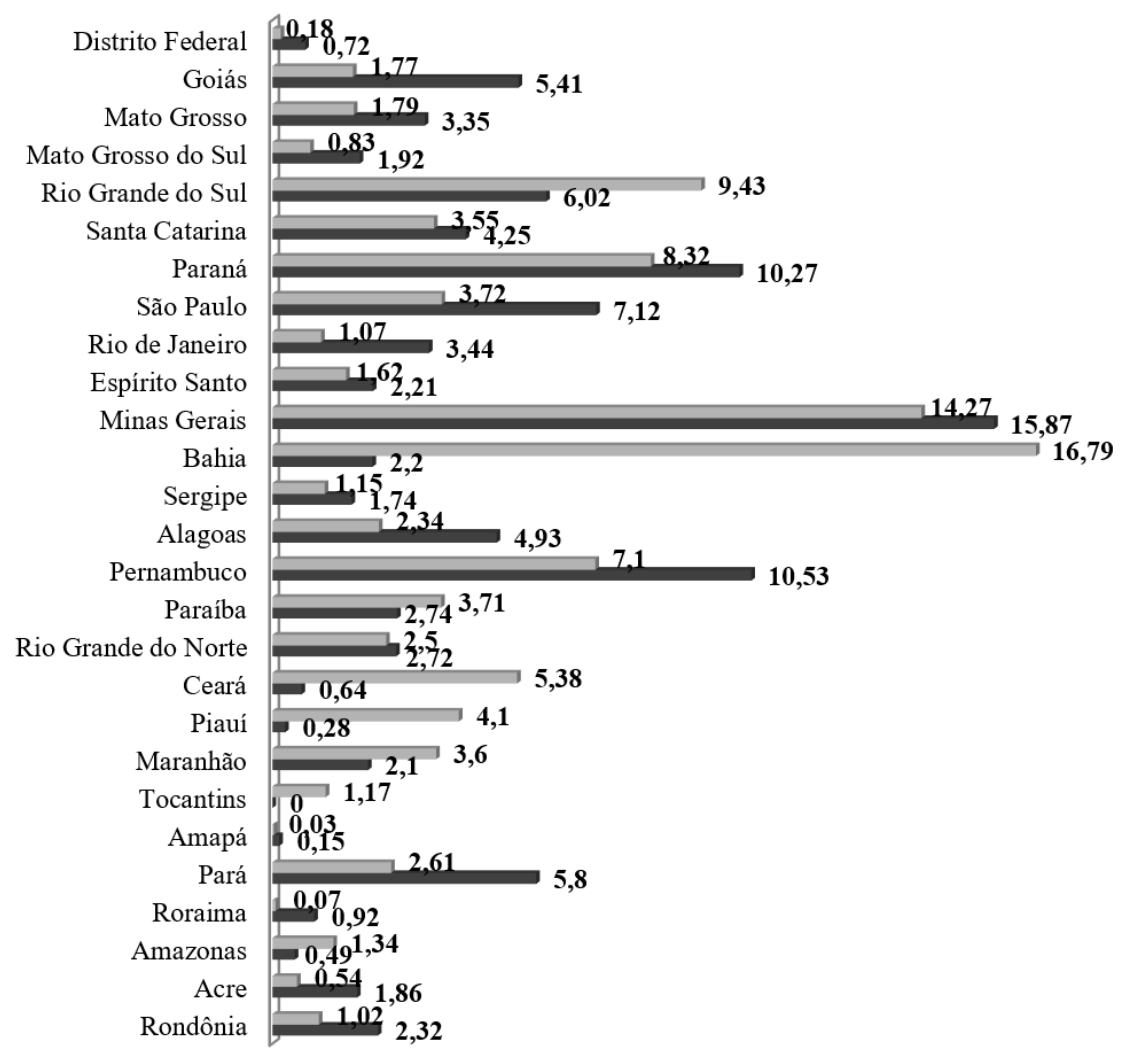

Figura 3 - Participação dos estados brasileiros no total nacional de estabelecimentos agropecuários com produção orgânica, em 2006 e 2017. Fonte: Elaborada pelos autores a partir dos dados dos Censos Agropecuários de 2006 e 2017 (Instituto Brasileiro de Geografia e Estatística, 2006, 2017).

No ano de 2006, dos 90.498 estabelecimentos com produção orgânica no Brasil, 16,79\% estavam no estado da Bahia, sendo o estado destaque. Minas Gerais, Rio Grande do Sul e Paraná também possuíam um percentual significativo do total nacional desses estabelecimentos. Os estados com menor número de estabelecimentos orgânicos eram Amapá, Roraima e Distrito Federal. Já no ano de 2017, os estabelecimentos com orgânicos do Brasil estavam em maior número em Minas Gerais, Pernambuco e Paraná, e em menor número, em Tocantins, sem nenhum estabelecimento, Amapá e Piauí. Chama a atenção a diminuição expressiva do número de estabelecimentos orgânicos da Bahia frente ao total orgânico nacional de 2006 para 2017.

O jornal eletrônico Correio da Bahia publicou, em 2018, uma reportagem a respeito de tal diminuição, indicando que a burocracia e os altos investimentos para obtenção da certificação têm atrapalhado os produtores, que são, na maioria, da agricultura familiar. Segundo o jornal, o investimento pode chegar a $\mathrm{R} \$ 80$ mil reais por ano, dependendo do tamanho da propriedade, e ainda precisa ser revalidado anualmente. Para pequenos agricultores o custo é em média $R \$$ 12 mil reais e muitos não conseguem pagar. Mas não são apenas os problemas de certificação que atrapalham os agricultores baianos. O jornal também cita fatores como: dificuldades para obtenção de insumos apropriados; falta de assistência técnica; logística prejudicada; gargalos na comercialização, entre outros. A certificação aparece como o quinto elemento a dificultar esse processo (Maynart, 2018).

Nesse sentido, o estado do Paraná, por meio da Superintendência Geral de Ciência, Tecnologia e Ensino Superior - SETI, em parceria com sete Instituições de Ensino Superior 
(IES), sendo elas: Universidade Estadual de Londrina (UEL), Universidade Estadual de Maringá (UEM), Universidade Estadual do Norte do Paraná (UENP), Universidade Estadual de Ponta Grossa (UEPG), Universidade Estadual do Paraná (Unespar), Universidade Estadual do Centro-Oeste (Unicentro), Universidade Estadual do Oeste do Paraná (Unioeste), mais o Centro Paranaense de Referência em Agroecologia (CPRA) e o Instituto de Tecnologia do Paraná (TECPAR), criou o Programa Paranaense de Certificação de Produtos Orgânicos (PPCPO), em 2009, que foi alterado em 2018 para Programa Paraná Mais Orgânico - PMO (Michellon et al., 2011a).

O programa foi criado para implantação de uma rede de apoio à certificação de alimentos orgânicos da agricultura e agroindústria familiar no Paraná, e, também, para gerar recursos humanos aptos a prestarem serviços de consultoria técnica, inspeção e auditoria para o processo de certificação orgânica. Atualmente, encontra-se na sua quarta fase, que teve início em 01 de julho de 2018 e irá se encerrar em 30 de junho de 2020, contando com mais de 50 profissionais envolvidos.

De acordo com Michellon et al. (2011 b), a parceria possui objetivos, como: implantar unidades e apoio à certificação da produção orgânica no Paraná; capacitar profissionais e estudantes para atuação futura em áreas de consultoria e auditoria de processos de certificação orgânica; formar a Rede Paranaense de Certificação de Produtos Orgânicos, com principal foco de aumentar a oferta de produtos certificados no mercado.

Por sua vez, outros estados reduziram bastante o número de estabelecimentos com produção orgânica frente ao total nacional, sendo eles Ceará e Piauí. Uma das explicações possíveis, segundo gerentes técnicos do Censo de 2017, é que, a partir de então, todos os respondentes que afirmavam seguir as práticas da agricultura orgânica eram necessariamente certificados, o que pode não ter ocorrido no Censo anterior.

Já com relação ao uso de agrotóxicos, a Tabela 4 apresenta o número de estabelecimentos agropecuários que usavam, não usavam e que usavam, mas não precisaram, em 2006 e 2017, nas regiões brasileiras.

Tabela 4 - Número de estabelecimentos agropecuários, segundo o uso de agrotóxicos, em 2006 e 2017, nas grandes regiões brasileiras

\begin{tabular}{|c|c|c|c|c|c|c|c|}
\hline \multirow[b]{2}{*}{ UF/PAÍS } & \multicolumn{7}{|c|}{2006} \\
\hline & Total & Utilizou & $\%$ & $\begin{array}{c}\text { Não } \\
\text { utilizou }\end{array}$ & $\%$ & $\begin{array}{l}\text { Utiliza, } \\
\text { mas não } \\
\text { precisou }\end{array}$ & $\%$ \\
\hline Norte & 475.778 & 59.375 & 12,48 & 405.617 & 85,25 & 10.786 & 2,27 \\
\hline Nordeste & 2.454 .060 & 458.606 & 18,69 & 1.928 .887 & 78,60 & 66.567 & 2,71 \\
\hline Sudeste & 922.097 & 225.605 & 24,47 & 660.165 & 71,59 & 36.327 & 3,94 \\
\hline Sul & 1.006 .203 & 600.865 & 59,72 & 373.447 & 37,11 & 31.891 & 3,17 \\
\hline Centro-Oeste & 317.498 & 51.626 & 16,26 & 254.065 & 80,02 & 11.807 & 3,72 \\
\hline \multirow[t]{2}{*}{ BRASIL } & 5.175 .636 & 1.396 .077 & 26,97 & 3.622 .181 & 69,99 & 157.378 & 3,04 \\
\hline & \multicolumn{7}{|c|}{2017} \\
\hline Norte & 580.446 & 126.459 & 21,79 & 429.467 & 73,99 & 19.883 & 3,42 \\
\hline Nordeste & 2.322 .495 & 552.237 & 23,78 & 1.684 .919 & 72,55 & 67.125 & 2,89 \\
\hline Sudeste & 969.258 & 324.879 & 33,52 & 618.259 & 63,79 & 24.451 & 2,52 \\
\hline Sul & 853.232 & 574.771 & 67,36 & 265.178 & 31,08 & 11.584 & 1,35 \\
\hline Centro-Oeste & 346.721 & 102.655 & 29,61 & 232.363 & 67,02 & 11.317 & 3,26 \\
\hline BRASIL & 5.072 .152 & 1.681 .001 & 33,14 & 3.230 .186 & 63,68 & 134.360 & 2,64 \\
\hline
\end{tabular}

Fonte: Elaborada pelos autores a partir dos dados dos Censos Agropecuários de 2006 e 2017 (Instituto Brasileiro de Geografia e Estatística, 2006, 2017). *A diferença para 100\%, em 2017, é devida a outras classificações não informadas. 
Em 2006, aproximadamente 27\% dos estabelecimentos agropecuários brasileiros usavam agrotóxicos, quase $70 \%$ dos estabelecimentos disseram não usar e apenas 3\% afirmaram que tinham agrotóxico, mas naquele ano não precisaram usar. Em 2017, o percentual dos estabelecimentos que usava agrotóxicos subiu para 33\% e caiu o número daqueles que não precisaram usar, mesmo tendo os produtos (2,64\%). Na região Sul, em 2006, quase 60\% dos estabelecimentos agropecuários dessa região utilizavam agrotóxicos. Por outro lado, nas regiões Norte e Centro-Oeste, mais de 80\% de seus estabelecimentos não usaram. Em 2017, $67 \%$ dos estabelecimentos da Região Sul produziam com agrotóxicos, número superior a 2006, com destaque para o aumento significativo de estabelecimentos que usavam na região Centro-Oeste. Todas as outras regiões tiveram um percentual menor dos estabelecimentos que não utilizaram agrotóxicos. Essas informações, de fato, sugerem um aumento geral da utilização dessas substâncias, o que, de certa forma, pode também contribuir para a redução do número de estabelecimentos com produção orgânica no Brasil.

De acordo com Ferreira (2013), a utilização de agrotóxicos, apesar dos problemas socioambientais causados, traz vários benefícios, pelo menos temporários, para os agentes envolvidos: sociedade, agricultores e indústrias. A utilização muitas vezes é necessária para a produção de alimentos. Com a crescente concentração desse mercado e os elevados lucros de empresas, principalmente multinacionais, é possível compreender por que esse é um segmento em expansão.

A quantidade de agrotóxicos usados no Brasil apresenta variabilidade ao longo dos anos em função de muitos elementos, como nível de ocorrência de pragas e doenças; variação das condições climáticas; preços dos agrotóxicos; preço dos produtos agrícolas; custos dos financiamentos para crédito agrícola, entre outros (Campanhola \& Bettiol (2003).

Analisando-se o percentual de estabelecimentos que usavam agrotóxicos das regiões frente ao total brasileiro dos estabelecimentos que usavam, as regiões líderes em 2006 e 2017 eram Sul e Nordeste. As regiões Norte, Sudeste e Centro-Oeste aumentaram esse percentual de 2006 para 2017 e a região Nordeste não apresentou alteração. A Figura 4 apresenta essas informações. Vale a pena destacar que a quantidade de estabelecimentos muitas vezes não reflete de fato a magnitude desse uso, pois regiões, como Centro-Oeste, apresentam poucos estabelecimentos, mas com grandes extensões.

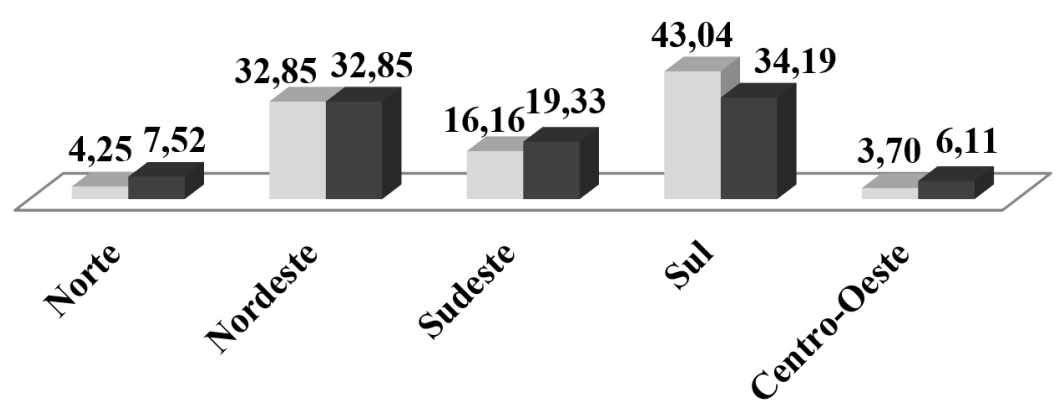

Figura 4 - Percentual dos estabelecimentos agropecuários das regiões brasileiras que usavam agrotóxicos frente ao total nacional que usavam em 2006 e 2017. Fonte: Elaborada pelos autores a partir dos dados dos Censos Agropecuários de 2006 e 2017 (Instituto Brasileiro de Geografia e Estatística, 2006, 2017). 
Para o ano de 2006, estava disponível a informação sobre a área dos estabelecimentos agropecuários com uso de agrotóxicos. Da área total da agricultura do Brasil, 30\% (100.211.650 hectares) eram produzidas com uso de agrotóxicos. A Figura 5 mostra a distribuição desse total entre as regiões brasileiras. Da área produzida com agrotóxicos no Brasil, 28\% (27.764.207 hectares) e 24\% (23.945.064 hectares) estavam nas regiões Centro-Oeste e Sul, respectivamente, sendo estas as mais expressivas. Novamente é importante lembrar que, embora a região Centro-Oeste apresentasse percentual bem baixo do número de estabelecimentos com uso de agrotóxicos frente ao total nacional dos estabelecimentos que utilizam, esses estabelecimentos eram de grandes extensões, deixando a região em destaque quando se analisa a área produzida com a utilização desses produtos.

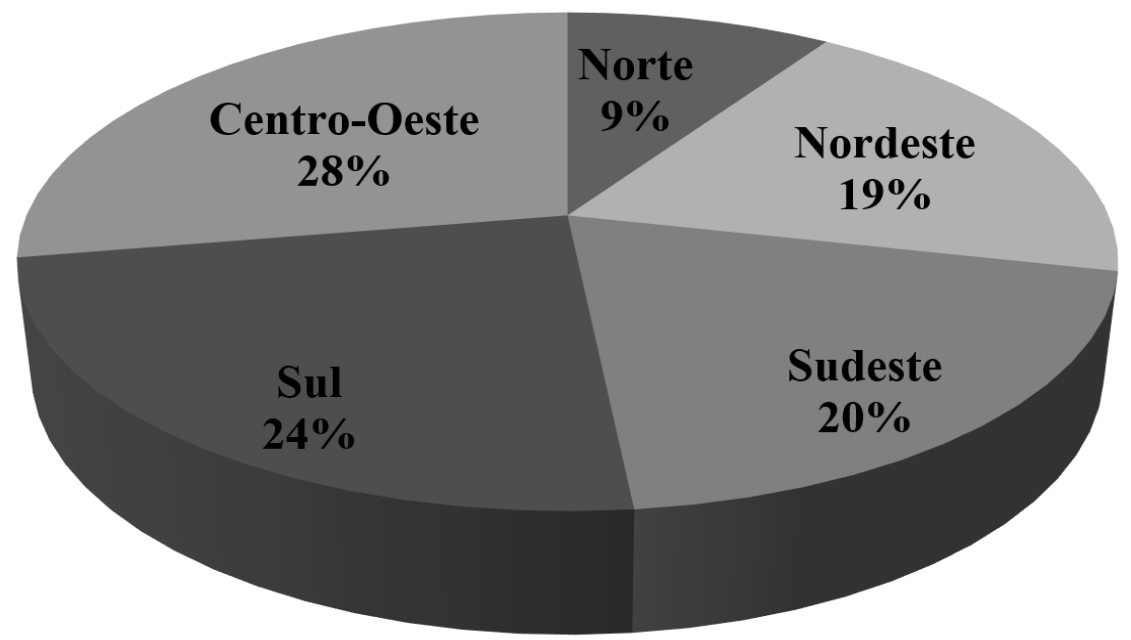

Figura 5 - Distribuição das terras do Brasil com uso de agrotóxicos nas regiões brasileiras, em 2006. Fonte: Elaborada pelos autores a partir dos dados dos Censos Agropecuários de 2006 e 2017 (Instituto Brasileiro de Geografia e Estatística, 2006, 2017).

A Tabela 5 apresenta o percentual dos estabelecimentos agropecuários de cada estado, segundo o uso de agrotóxicos em 2006 e 2017.

No ano de 2006, os estados da região Sul do Brasil e o Distrito Federal eram destaque, apresentavam-se com os maiores percentuais de estabelecimentos com uso de agrotóxicos frente a seus totais estaduais de estabelecimentos. Já os estados com os menores percentuais eram alguns das regiões Norte e Nordeste. Já no ano de 2017, os estados com mais da metade de seus estabelecimentos produzindo com agrotóxicos eram: Rondônia, Espírito Santo, Paraná, Santa Catarina e Rio Grande do Sul. Mais uma vez, os estados da região Sul eram os líderes em uso dessas substâncias. Chama a atenção o fato de que os estados que, em 2006, tinham menos de $10 \%$ de seus estabelecimentos usando agrotóxico, em 2017, tiveram um aumento expressivo relativo ao total de seus estabelecimentos agropecuários. Praticamente todos os estados tiveram aumento do percentual de estabelecimentos usando agrotóxicos de 2006 para 2017 e, na maioria, houve redução daqueles que usavam, mas não precisaram. 
Tabela 5 - Percentual do número de estabelecimentos agropecuários, segundo o uso de agrotóxicos em 2006 e 2017, nos estados brasileiros

\begin{tabular}{|c|c|c|c|c|c|c|c|c|}
\hline \multirow[b]{2}{*}{ Estados } & \multicolumn{4}{|c|}{2006} & \multicolumn{4}{|c|}{2017} \\
\hline & $\begin{array}{l}\overline{\mathbb{J}} \\
\stackrel{\text { o }}{\bullet}\end{array}$ & 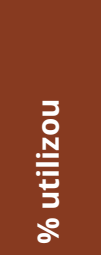 & 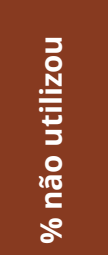 & 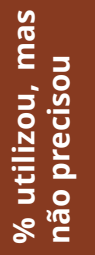 & 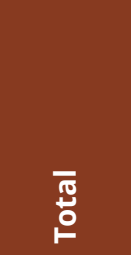 & 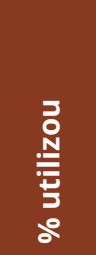 & 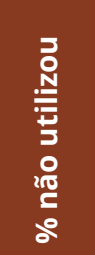 & 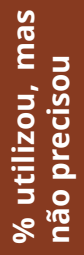 \\
\hline Rondônia & 87.078 & 35,77 & 59,78 & 4,46 & 91.437 & 51,59 & 41,80 & 6,44 \\
\hline Acre & 29.483 & 5,84 & 91,80 & 2,36 & 37.343 & 20,30 & 76,80 & 2,36 \\
\hline Amazonas & 66.784 & 5,59 & 93,04 & 1,38 & 80.914 & 11,46 & 84,85 & 1,40 \\
\hline Roraima & 10.310 & 6,25 & 91,59 & 2,16 & 16.850 & 14,38 & 83,00 & 2,53 \\
\hline Pará & 222.029 & 7,38 & 90,84 & 1,78 & 281.704 & 15,58 & 80,43 & 3,25 \\
\hline Amapá & 3.527 & 6,66 & 91,58 & 1,76 & 8.507 & 12,18 & 84,86 & 1,03 \\
\hline Tocantins & 56.567 & 9,77 & 88,38 & 1,85 & 63.691 & 23,69 & 72,44 & 3,63 \\
\hline Maranhão & 287.039 & 10,83 & 87,67 & 1,50 & 219.765 & 25,36 & 67,60 & 2,48 \\
\hline Piauí & 245.378 & 14,14 & 83,06 & 2,80 & 245.623 & 19,33 & 77,26 & 2,81 \\
\hline Ceará & 381.017 & 29,44 & 67,51 & 3,05 & 394.317 & 32,69 & 63,72 & 2,93 \\
\hline $\begin{array}{l}\text { Rio Grande } \\
\text { do Norte }\end{array}$ & 83.053 & 29,09 & 66,70 & 4,20 & 63.411 & 34,70 & 60,94 & 4,19 \\
\hline Paraíba & 167.286 & 30,37 & 66,41 & 3,22 & 163.217 & 32,00 & 63,88 & 3,89 \\
\hline Pernambuco & 304.790 & 22,42 & 74,28 & 3,30 & 281.675 & 22,28 & 74,05 & 3,31 \\
\hline Alagoas & 123.332 & 20,77 & 76,79 & 2,44 & 98.534 & 30,92 & 66,26 & 2,69 \\
\hline Sergipe & 100.607 & 21,81 & 73,66 & 4,52 & 93.333 & 28,69 & 68,11 & 2,88 \\
\hline Bahia & 761.558 & 11,79 & 85,94 & 2,27 & 762.620 & 16,51 & 80,64 & 2,56 \\
\hline Minas Gerais & 551.621 & 18,78 & 78,00 & 3,22 & 607.448 & 27,38 & 70,01 & 2,46 \\
\hline Espírito Santo & 84.361 & 35,77 & 58,62 & 5,61 & 108.010 & 61,12 & 34,67 & 4,13 \\
\hline Rio de Janeiro & 58.493 & 23,48 & 73,94 & 2,57 & 65.157 & 24,21 & 74,23 & 1,38 \\
\hline São Paulo & 227.622 & 34,30 & 60,28 & 5,42 & 188.643 & 40,71 & 56,82 & 2,19 \\
\hline Paraná & 371.063 & 54,64 & 41,48 & 3,88 & 305.115 & 62,05 & 36,01 & 1,72 \\
\hline $\begin{array}{l}\text { Santa } \\
\text { Catarina }\end{array}$ & 193.668 & 64,16 & 32,99 & 2,85 & 183.065 & 70,66 & 27,71 & 1,41 \\
\hline $\begin{array}{l}\text { Rio Grande } \\
\text { do Sul }\end{array}$ & 441.472 & 62,03 & 35,25 & 2,71 & 365.052 & 70,15 & 28,65 & 1,03 \\
\hline $\begin{array}{l}\text { Mato Grosso } \\
\text { do Sul }\end{array}$ & 64.864 & 17,58 & 79,20 & 3,22 & 70.710 & 21,99 & 75,66 & 2,20 \\
\hline Mato Grosso & 112.987 & 17,20 & 79,62 & 3,18 & 118.676 & 40,49 & 54,51 & 4,83 \\
\hline Goiás & 135.692 & 13,96 & 81,66 & 4,38 & 152.089 & 24,18 & 73,22 & 2,56 \\
\hline $\begin{array}{l}\text { Distrito } \\
\text { Federal }\end{array}$ & 3.955 & 46,68 & 48,90 & 4,42 & 5.246 & 43,60 & 53,77 & 2,55 \\
\hline
\end{tabular}

Fonte: Elaborada pelos autores a partir dos dados dos Censos Agropecuários de 2006 e 2017 (Instituto Brasileiro de Geografia e Estatística, 2006, 2017). *A diferença para 100\% em 2017 é devida a outras classificações não informadas.

Ferreira (2013) aponta que a política fiscal que é adotada no Brasil acaba por incentivar o uso de agrotóxicos nas lavouras, porque são oferecidas reduções e até mesmo isenções de alguns impostos ${ }^{3}$. Além disso, são comercializados no Brasil produtos proibidos em seu país de

\footnotetext{
3 Segundo Ferreira (2013, p. 299), o Brasil “[...] incentiva a utilização de tais produtos através da redução de Imposto sobre Circulação de Mercadoria, realizada com base no Convênio ICMS 100/97, e da isenção do Imposto sobre Produtos Industrializados, realizada com base no Decreto $n^{\circ} 7.660$, de 23 de dezembro de 2011. Acrescente-se ainda que o Decreto 5.630/053 isenta da cobrança de Programa de Integração Social/ Programa de Formação do Patrimônio do Servidor (PIS/PASEP) e de Contribuição".
} 
origem. Muitos países desenvolvidos, produtores mundiais de agrotóxicos, impõem restrições e controles rígidos para comercialização em seus territórios, mas não têm controle sobre as exportações para os países em desenvolvimento.

Além disso, a ABRASCO (Associação Brasileira de Saúde Coletiva, 2012) alerta que, no Brasil, a situação se agrava ainda mais pelas constantes pressões exercidas sobre os órgãos reguladores para flexibilizar a legislação. Destacam-se, nessas pressões, a bancada ruralista e as corporações transnacionais, responsáveis pelo agronegócio e pela indução e ampliação do pacote tecnológico agrotóxicos-transgênicos-fertilizantes.

Para Rigotto et al. (2014), o aumento do uso de agrotóxicos no Brasil está associado também à intensa liberação do uso de sementes transgênicas para cultivo e a difusão destas nas áreas agricultáveis. A partir disso, houve aumento do uso de herbicidas, fungicidas e inseticidas. Além disso, segundo os autores (Rigotto et al., 2014, p. 2), "Tal modelo de produção tem levado ao surgimento de superpragas, com grandes prejuízos econômicos e pressões para importação de agrotóxicos proibidos no país e pelo desmanche da atual legislação brasileira sobre agrotóxicos".

Campanhola \& Bettiol (2003) ressaltam que os agrotóxicos foram inseridos e fizeram parte do processo de modernização da agricultura, que ocorreu a partir da década de 1960, cujo objetivo era aumentar a produtividade da agricultura para atender à demanda mundial crescente por alimentos. No entanto, o uso generalizado e demasiado desses produtos fez aparecer muitos problemas ambientais e de saúde pública.

A fim de identificar quais estados brasileiros eram os líderes em estabelecimentos com uso de agrotóxicos frente ao total nacional de estabelecimentos que os usavam em 2006 e 2017, formulou-se a Tabela 6.

É possível verificar que, em 2006, os estados Rio Grande do Sul e Paraná eram os estados onde se encontrava o maior número de estabelecimentos produzindo com agrotóxicos. Também se destacavam Santa Catarina, Ceará, Minas Gerais e Bahia. Já os estados Amapá, Roraima, Acre, Distrito Federal e Amazonas eram os estados com menor número de estabelecimentos usando agrotóxicos frente ao total nacional. Em 2017, se manteve o padrão dos estados líderes e dos estados com menor número de estabelecimentos usando agroquímicos de 2006, porém o estado de Minas Gerais ocupou o lugar de Santa Catarina, tornando-se o terceiro estado com maior número de estabelecimentos usando agrotóxicos. A maioria dos estados aumentou o percentual de estabelecimentos usando agrotóxicos frente ao total nacional de 2006 para 2017.

Tabela 6 - Participação dos estados brasileiros no total nacional de estabelecimentos agropecuários com uso de agrotóxicos, em 2006 e 2017

\begin{tabular}{lcccc}
\multicolumn{1}{c}{ UF/PAís } & Total & \% & Total & \% \\
\cline { 2 - 5 } BRASIL & \multicolumn{2}{c}{$\mathbf{2 0 0 6}$} & & $\mathbf{2 0 1 7}$ \\
Rondônia & $\mathbf{1 . 3 9 6 . 0 7 7}$ & $\mathbf{1 0 0}$ & $\mathbf{1 . 6 8 1 . 0 0 1}$ & $\mathbf{1 0 0}$ \\
Acre & 31.144 & 2,23 & 47.173 & 2,81 \\
Amazonas & 1.722 & 0,12 & 7.580 & 0,45 \\
Roraima & 3.730 & 0,27 & 9.272 & 0,55 \\
Pará & 644 & 0,05 & 2.423 & 0,14 \\
Amapá & 16.376 & 1,17 & 43.889 & 2,61 \\
Tocantins & 235 & 0,02 & 1.036 & 0,06 \\
Maranhão & 5.524 & 0,40 & 15.086 & 0,90 \\
Piauí & 31.091 & 2,23 & 55.728 & 3,32 \\
Ceará & 34.686 & 2,48 & 47.474 & 2,82 \\
Rio Grande do Norte & 112.154 & 8,03 & 128.913 & 7,67 \\
\hline
\end{tabular}

Fonte: Elaborada pelos autores a partir dos dados dos Censos Agropecuários de 2006 e 2017 (Instituto Brasileiro de Geografia e Estatística, 2006, 2017). 
Tabela 6 - Continued...

\begin{tabular}{lcccc}
\multicolumn{1}{c}{ UF/PAís } & Total & \% & Total & \% \\
\cline { 2 - 5 } Paraíba & & $\mathbf{2 0 0 6}$ & & $\mathbf{2 0 1 7}$ \\
Pernambuco & 50.806 & 3,64 & 52.227 & 3,11 \\
Alagoas & 68.329 & 4,89 & 62.766 & 3,73 \\
Sergipe & 25.621 & 1,84 & 30.464 & 1,81 \\
Bahia & 21.947 & 1,57 & 26.779 & 1,59 \\
Minas Gerais & 89.809 & 6,43 & 125.885 & 7,49 \\
Espírito Santo & 103.617 & 7,42 & 166.300 & 9,89 \\
Rio de Janeiro & 30.180 & 2,16 & 66.015 & 3,93 \\
São Paulo & 13.736 & 0,98 & 15.773 & 0,94 \\
Paraná & 78.072 & 5,59 & 76.791 & 4,57 \\
Santa Catarina & 202.758 & 14,52 & 189.310 & 11,26 \\
Rio Grande do Sul & 124.256 & 8,90 & 129.362 & 7,70 \\
Mato Grosso do Sul & 273.851 & 19,62 & 256.099 & 15,23 \\
Mato Grosso & 11.403 & 0,82 & 15.547 & 0,92 \\
Goiás & 19.436 & 1,39 & 48.048 & 2,86 \\
Distrito Federal & 18.941 & 1,36 & 36.773 & 2,19 \\
\hline
\end{tabular}

Fonte: Elaborada pelos autores a partir dos dados dos Censos Agropecuários de 2006 e 2017 (Instituto Brasileiro de Geografia e Estatística, 2006, 2017).

No entanto, no quesito área total dos estabelecimentos com uso de agrotóxicos dos estados frente ao total brasileiro da área agrícola produzida com agrotóxicos, o cenário é um pouco diferente. É importante observar que essas informações ainda não estão disponíveis para o Censo Agropecuário 2017. A Figura 6 mostra os estados líderes em percentual de área com utilização de agrotóxicos do ano de 2006.

Verifica-se que Mato Grosso era o estado com a maior quantidade de área produzida com agrotóxicos frente à área total do Brasil que utilizava esses produtos (15.236.726 hectares), seguido pelo Rio Grande do Sul (11.134.151 hectares) e por Minas Gerais (10.079.752 hectares). Esses dados também refletem o fato de que, embora no Mato Grosso se encontrassem poucos estabelecimentos que usavam agrotóxicos comparados com o total nacional (1,39\%), esses estabelecimentos possuíam grandes extensões de terras, deixando o estado líder na quantidade de área produzida com uso de agrotóxicos no Brasil. Segundo Pignati et al. (2017), em 2015, o estado do Mato Grosso plantou 13,9 milhões de hectares e consumiu 207 milhões de litros de agrotóxicos, seguido do Paraná, com 10,2 milhões de hectares, consumindo 135 milhões de litros de agrotóxicos, e do Rio Grande do Sul, com 8,5 milhões de hectares plantados, utilizando 134 milhões de litros de agrotóxicos. Segundo os autores, a soja foi a cultura que mais utilizou agrotóxicos no Brasil, representando $63 \%$ do total, seguida do milho (13\%) e da cana-de-açúcar (5\%).

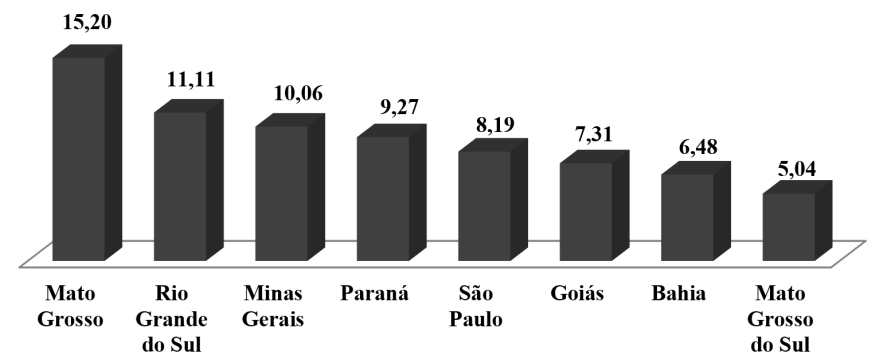

Figura 6 - Estados com maior percentual de área produzida com uso de agrotóxicos frente à área total brasileira com uso dessas substâncias, em 2006. Fonte: Elaborada pelos autores a partir dos dados dos Censos Agropecuários de 2006 e 2017 (Instituto Brasileiro de Geografia e Estatística, 2006, 2017). 
Ferreira (2013) relata que a cultura da cana-de-açúcar, juntamente com a cultura da soja, do milho e do algodão, concentra mais da metade do consumo de agrotóxicos no País. Pode-se perceber que os estados que mais utilizam agrotóxicos são aqueles conhecidos como "celeiros" do agronegócio brasileiro. Em 2017, Mato Grosso foi o maior produtor de soja e milho do Brasil, seguido de Rio Grande do Sul e Paraná, na produção de soja, e de Paraná e Goiás, na produção de milho. O estado de São Paulo é o líder em produção de cana-de-açúcar e os estados do Rio Grande do Sul, Paraná e São Paulo são os maiores produtores de trigo (Instituto Brasileiro de Geografia e Estatística, 2017). Dessa forma, é possível fazer uma associação direta de que os estados que são os maiores produtores de commodities do Brasil são também os maiores consumidores de agrotóxicos.

\section{CONSIDERAÇÕES FINAIS}

Este artigo se propôs a traçar um panorama da agricultura orgânica e do uso de agrotóxicos no Brasil a partir dos Censos Agropecuários de 2006 e 2017, a fim de analisar as evoluções nesse período. Como o País é o maior consumidor de agrotóxicos do mundo, se torna importante conhecer as regiões e os estados que se destacam no uso desses produtos. Além disso, torna-se importante verificar também os números da agricultura orgânica brasileira como uma forma alternativa de produção e consumo.

O comércio e o uso mundial de agrotóxicos aumentaram a uma taxa anual de 10\% entre as décadas de 1950 e 1980. No Brasil, se intensificaram após a década de 1940. Durante todo o período de 1975 a 2007, o País sempre esteve entre os seis maiores mercados de agrotóxicos do mundo, o que pode ser explicado pelo aumento da produção de commodities agrícolas, que usam intensivamente esses insumos. Atualmente, a China tornou-se o maior exportador mundial de agrotóxicos e o Brasil, a partir de 2012, o maior importador mundial.

$\mathrm{O}$ aumento do uso de agrotóxicos ao longo do tempo esteve associado à necessidade de aumentar a produtividade para atender à demanda crescente por alimentos, ao aumento de pragas e doenças, à liberação do uso de sementes modificadas, às pressões de grupos de interesse e às flexibilizações das legislações.

Em 2006, cerca de $27 \%$ dos estabelecimentos agropecuários brasileiros usavam agrotóxicos; já em 2017, esse percentual subiu para 33\%. Analisando-se o percentual de estabelecimentos que usava agrotóxicos das regiões frente ao total brasileiro dos estabelecimentos que os usavam, as regiões líderes em 2006 e 2017 eram Sul e Nordeste.

Da área total da agricultura do Brasil, em 2006, 30\% (100.211.650 hectares) eram produzidas com uso de agrotóxicos. Dessa área, $28 \%$ e $24 \%$ estavam nas regiões Centro-Oeste e Sul, respectivamente. Embora a região Centro-Oeste apresentasse percentual bem baixo do número de estabelecimentos com uso de agrotóxicos frente ao total nacional dos estabelecimentos que utilizam, esses estabelecimentos eram de grandes extensões, deixando a região em destaque quando se analisa a área produzida com a utilização desses produtos. O estado do Mato Grosso, por sua vez, era o estado com a maior quantidade de área produzida com agrotóxicos frente à área total do Brasil, seguido pelo Rio Grande do Sul e por Minas Gerais. As informações sobre área produzida com a utilização de agrotóxicos ainda não estavam disponíveis para o ano de 2017, no momento da pesquisa.

Os estados da região Sul, somados com Ceará e Minas Gerais, eram os estados onde se encontrava o maior número de estabelecimentos produzindo com agrotóxicos do total brasileiro, em 2006. Em 2017, manteve-se esse padrão, porém o estado de Minas Gerais ocupou o lugar de Santa Catarina, tornando-se o terceiro estado com maior número de estabelecimentos 
usando agrotóxicos. A maioria dos estados aumentou o percentual de estabelecimentos usando agrotóxicos frente ao total nacional de 2006 para 2017.

Com relação à agricultura orgânica, no ano de 2006, havia, no Brasil, 90.498 estabelecimentos com essa atividade; já em 2017, esse valor passou para 68.717. Em 2006, esse valor representava $1,75 \%$ dos estabelecimentos e, em 2017, 1,35\%. Percebe-se assim que houve uma redução relativa do número de estabelecimentos com agricultura orgânica no Brasil de 2006 para 2017, o que pode ser explicado pelo fato de que, em 2017, todos eram necessariamente certificados.

Além disso, devem-se levar em consideração os custos elevados para as certificações, as dificuldades de transporte dos produtos até os locais de comercialização, os problemas de organização, a falta de estímulo das políticas públicas, o papel dos grandes supermercados em dificultar a comercialização por apresentarem elevadas exigências, entre outros fatores. Esses elementos colocam muitas barreiras e entraves ao desenvolvimento da produção e comercialização de orgânicos no Brasil.

Em 2006, estavam, na região Nordeste, 46,7\% desses estabelecimentos, $21 \%$ na região Sul e $20 \%$ na região Sudeste. Já em 2017, 28\% estavam na região Sudeste, $27 \%$ na região Nordeste e $20 \%$ na região Sul. No ano de 2006, a maior quantidade de área com agricultura orgânica estava na região Nordeste, seguida pela região Centro-Oeste, a qual, embora apresentasse poucos estabelecimentos com essa atividade, estes eram de grandes extensões. Com relação aos estabelecimentos do Brasil com agricultura orgânica, em 2006, 16,79\% estavam no estado da Bahia, sendo o estado destaque. Minas Gerais, Rio Grande do Sul e Paraná também possuíam um percentual significativo do total nacional desses estabelecimentos. Já no ano de 2017, os estabelecimentos com orgânicos do Brasil estavam em maior número em Minas Gerais, Pernambuco e Paraná, e em menor número, em Tocantins, sem nenhum estabelecimento, Amapá e Piauí.

Um dos questionamentos levantados neste artigo é o problema da possível superestimação das informações sobre a agricultura orgânica nos Censos. Tal impasse é devido ao fato de que, embora a definição de agricultura orgânica deva ser baseada na Lei $n^{\circ} 10.831$ e que deva ser considerado orgânico o produtor que faz parte do Cadastro Nacional de Produtores Orgânicos - o que é possível somente se estiver certificado -, na aplicação prática, isso nem sempre acontece.

Este trabalho não pretende esgotar as discussões sobre essa temática e sugere que complementações e novas avaliações sejam feitas assim que ocorram as publicações definitivas do Censo Agropecuário de 2017. Embora existam algumas limitações e dificuldades, a pesquisa conseguiu cumprir seu objetivo.

As discussões sobre o uso de agrotóxicos e a agricultura orgânica devem permanecer na agenda, pois são temas importantes, que afetam as condições de vida da sociedade. A busca de maior qualidade de vida está colocando em questão o uso indiscriminado dessas substâncias prejudiciais à saúde, como os agrotóxicos, e por isso merecem destaque também na pesquisa científica.

\section{REFERÊNCIAS}

Alves Filho, J. P. (2002). Uso de agrotóxicos no Brasil: controle social e interesses corporativos. São Paulo: Annablume/FAPESP.

Assis, R. L. (2005). Agricultura orgânica e agroecologia: questões conceituais e processo de conversão (Documentos, 196). Seropédica: EMBRAPA. Recuperado em 12 agosto de 2018, de https://www.infoteca.cnptia.embrapa.br/bitstream/doc/628360/1/doc196.pdf 
Associação Brasileira de Saúde Coletiva - ABRASCO. (2012). Dossiê: uma alerta sobre os impactos dos agrotóxicos na Saúde. Parte 1. Agrotóxicos, segurança alimentar e saúde. Rio de Janeiro: ABRASCO. Recuperado em 25 setembro de 2020, de http://www.cvs.saude. sp.gov.br/zip/Dossie_Abrasco_01.pdf

Azevedo, E. (2018). Alimentos Orgânicos: ampliando conceitos de saúde humana, ambiental e social. Senac. Recuperado em 25 de setembro, 2020, de https://books.google.com.br/ books?hl=pt-BR\&lr=\&id=1XF_DwAAQBAJ\&oi=fnd\&pg=PT2\&dq=Elaine+de+Azevedo\&o ts=SXYMY2HRvr\&sig=qrkf-Oj_g-sR--Od4Xf2m5SKcTo\#v=onepage \&q=Elaine\%20de\%20 Azevedo\&f=false

Brasil. (1989, 11 julho). Lei nº 7.802 de 11 de julho de 1989. Dispõe sobre agrotóxicos e dá outras providências. Diário Oficial [da] República Federativa do Brasil, Brasília.

Brasil. (2003, 23 dezembro). Lei no 10.831 de 23 de dezembro de 2003. Dispõe sobre a agricultura orgânica e dá outras providências. Diário Oficial [da] República Federativa do Brasil, Brasília.

Brasil. Ministério da Agricultura Pecuária e Abastecimento - MAPA. (2017). Folder- Produto Orgânico. Brasília: MAPA. Recuperado em 16 outubro, 2018, de http://www.agricultura. gov.br/assuntos/sustentabilidade/organicos/arquivos-publicacoes-organicos/folderorganico_web.pdf/view

Campanhola, C., \& Bettiol, W. (2003). Panorama sobre o uso de agrotóxicos no Brasil. In C. Campanhola \& W. Bettiol. Métodos alternativos de controle fitossanitário. Jaguariúna: Embrapa Meio Ambiente. Recuperado em 26 setembro de 2020, de https://www.alice. cnptia.embrapa.br/bitstream/doc/1076531/1/Campanholapanorama.pdf

Campanhola, C., \& Valarini, P. J. (2001). A agricultura orgânica e seu potencial parao pequeno agricultor. Cadernos de Ciência \& Tecnologia, 18(3), 69-101. Recuperado em 20 agosto de 2018, de http://seer.sct.embrapa.br/index.php/cct/article/view/8851

Caporal, F. R. (2009). Agroecologia: uma nova ciência para apoiar a transição a agriculturas mais sustentáveis. Embrapa Caprinos e Ovinos-Outras publicações científicas (ALICE). Recuperado em 12 agosto de 2018, de http://reformaagrariaemdados.org.br/sites/default/ files/Agroecologia,\%20ciencia\%20para\%20a\%20agricultura\%20mais\%20sustentavel\%20 -\%20Francisco\%20Caporal.pdf

Federação Internacional dos Movimentos de Agricultura Orgânica - IFOAM. (2018a). Definição de agricultura orgânica. Recuperado em 10 agosto, 2018, de https://www.ifoam.bio/en/ organic-landmarks/definition-organic-agriculture

Federação Internacional dos Movimentos de Agricultura Orgânica - IFOAM. (2018b). Annual Reports. Recuperado em 11 agosto de 2018, de https://www.ifoam.bio/en/our-library/ annual-reports

Ferreira, M. L. P. C. (2013). A regulação do uso dos agrotóxicos no Brasil: uma proposta para um direito de sustentabilidade(Tese de doutorado). Centro de Ciências Jurídicas, Programa de Pós-Graduação em Direito, Florianópolis.

Fonseca, M. F. A. C. (2009). Agricultura orgânica: regulamentos técnicos e acesso aos mercados dos produtos orgânicos no Brasil. Niterói: PESAGRO-RIO.

Instituto Brasileiro de Geografia e Estatística - IBGE. (2006). Censo Agropecuário 2006. Recuperado em 18 junho de 2018, de https://sidra.ibge.gov.br/pesquisa/censo-agropecuario/censoagropecuario-2006/segunda-apuracao 
Instituto Brasileiro de Geografia e Estatística - IBGE. (2017). Censo Agropecuário 2017. Recuperado em 18 junho de 2018, de https://sidra.ibge.gov.br/pesquisa/censo-agropecuario/censoagropecuario-2017

Londres, F. (2011). Agrotóxicos no Brasil: um guia para ação em defesa da vida. Rio de Janeiro: AS-PTA-Assessoria e Serviços a Projetos em Agricultura Alternativa.

Lourenço, A. V., Schneider, S., \& Gazolla, M. (2017). A agricultura orgânica no Brasil: um perfil a partir do censo agropecuário 2006. Extensão Rural, 24(1), 42-61. Recuperado em 16 outubro de 2018, de https://periodicos.ufsm.br/extensaorural/article/view/24514

Madail, J. C. M., Belarmino, L. C., \& Bini, D. A. (2011). Evolução da produção e mercado de produtos orgânicos no Brasil e no mundo. Revista Científica da Ajes, 2(3). Recuperado em 24 setembro de 2020, de http://revista.ajes.edu.br/index.php/rca/article/view/53

Maynart, G. (2018). Só 0,2\% dos agricultores da Bahia comprovam que produzem orgânicos. Correio. Recuperado em 25 de setembro de 2020, de https://www.correio24horas.com. $\mathrm{br} /$ noticia/nid/so-02-dos-agricultores-da-bahia-comprovam-que-produzem-organicos/

Michellon, E., Rocha, C. H., Martins, F. R. C., Kawakami, J., Roveda, L. F., Kawano, L. C., Ventura, M. U., Garcia, R. C., Macedo, R. B., \& Wihelm, V. I. (2011a). Paraná mais orgânico: relatos de experiências de certificação pública de produtos orgânicos. Curitiba: CRV.

Michellon, E., Rosa, G. M., Kawakami, J., Branco, K. B. Z. F., \& Carvalho, T. M. M. (2011b). Certificação pública de produtos orgânicos: a experiência paranaense. Maringá: Chichetec.

Moraes, M. L., \& Michellon, E. (2012). Inovações na agroecologia e o desenvolvimento sustentável. In Anais do $50^{\circ}$ Congresso da SOBER. Brasília: SOBER.

Ormond, J. G. P., De Paula, S. R. L., Faveret Filho, P., \& Da Rocha, L. T. M. (2002). Agricultura orgânica: quando o passado é futuro. BNDES Setorial, 15, 3-34. Recuperado em 11 agosto, 2018, de https://web.bndes.gov.br/bib/jspui/handle/1408/2479

Pelaez, V., Teodorovicz, T., Guimarães, T. A., Da Silva, L. R., Moreau, D. \& Mizukawa, G. (2016). A dinâmica do comércio internacional de agrotóxicos. Revista de Política Agrícola, 2, 3952. Recuperado em 24 agosto de 2018, file:///C:/Users/acer/Downloads/Revista\%20de\%20 Pol\%C3\%ADtica\%20Agr\%C3\%ADcola\%20n2-2016.pdf

Pignati, W. A., Lima, F. A. N. S., De Lara, S. S., Correa, M. L. M., Barbosa, J. R., \& Leão, L. H. C., \& Pignatti, M. G. (2017). Distribuição espacial do uso de agrotóxicos no Brasil: uma ferramenta para a Vigilância em Saúde. Ciência \& Saúde Coletiva, 22, 3281-3293. Recuperado em 06 outubro de 2018, de https://www.scielosp.org/scielo.php?pid=S1413$81232017001003281 \&$ script=sci_arttext\&tlng=es

Rigotto, R. M., Vasconcelos, D. P., \& Rocha, M. M. (2014). Uso de agrotóxicos no Brasil e problemas para a saúde pública. Cadernos de Saude Publica, 30, 1360-1362. Recuperado em 26 setembro de 2020, de https://www.scielosp.org/article/csp/2014.v30n7/1360-1362/pt/\#

Serviço Brasileiro de Apoio às Micro e Pequenas Empresas - SEBRAE. (2018). Orgânicos SEBRAE: Avaliação da Conformidade Orgânica. Recuperado em 16 outubro de 2018, de http://www. agricultura.gov.br/assuntos/camaras-setoriais-tematicas/documentos/camaras-tematicas/ agricultura-organica/2018/32a-ro/organicos-sebrae-avaliacao-da-conformidade-organicae-sebraetec-ctao-27-4-18.pdf/view

Sversutti, W. D., Oliveira, A. R. R., \& Michellon, E. (2009). Tecnologias alternativas na agricultura sustentável. In Anais do XVIII Encontro Anual de Iniciação Científica - EAIC, Londrina: UEL. 
Terra, F. H. B. (2008). A Indústria de Agrotóxicos no Brasil(Dissertação de mestrado). Programa de Pós-Graduação em Desenvolvimento Econômico, Universidade Federal do Paraná, Curitiba.

Whitacker, G. M. (2012). Agricultura orgânica: estratégia capitalista para a (re) produção do espaço rural. Geografia em Atos (Online), 1(12), 75-94. Recuperado em 12 agosto de 2018, de http://revista.fct.unesp.br/index.php/geografiaematos/article/view/1613

Data de submissão: 14 de junho de 2019

Data de aceite: 18 de dezembro de 2020.

Classificação JEL: Q53, Q56, Q57 